\title{
TESTING OF THE RELATIVE PRECISION IN LOCAL NETWORK WITH USE OF THE TRIMBLE GEO XR GNSS RECEIVERS
}

\author{
Martin Štroner, Rudolf Urban, Jakub Královič \\ Department of Special Geodesy \\ Faculty of Civil Engineering \\ Czech Technical University in Prague \\ Czech Republic
}

\begin{abstract}
The paper deal with testing of different GNSS measurement methods in highly accurate network for the objectives of engineering surveying. The test is comprised of a set of measurement acquired by particular GNSS methods with different observation length. For purposes of the test, an appropriate network of five points in local system was created and accurately trigonometrically measured. The result of testing is a comparison of individual methods in position using two dimensional congruent transformation and in height using one dimensional congruent transformation.
\end{abstract}

Keywords: high precision network; GNSS method; testing; precision evaluation

\section{Introduction}

Global Navigation Satellite Systems (GNSS) and their use in the field of geodesy, engineering surveying is currently due to the affordability of the receivers and the possibility of using relatively inexpensive network RTK solution to determine the coordinates very common. Functionality, reliability and accuracy, however, is not for ordinary surveyors in practice simple and straightforward matter. In many cases the receiver and the software is a black box, which just provides the coordinates. Testing of the accuracy and reliability is then usually focused on the characteristics global in the national and absolute meaning as in (Vilímková, 2007) or (Urban, Štroner, and Kovařík, 2013). These characteristics are however not essential, e.g. in engineering surveying. There is in many cases much more relevant local precision, for example within a relatively small building site. Therefore there was designed, implemented and evaluated a simple local test of the accuracy of GNSS measurement, which was 
partly carried out in during processing of a diploma thesis of Ing. Jakub Královic (Královič, 2013).).

In addition to commonly used methods (fast static and RTK method) was also tested a method RTK using simultaneous measurement of multiple receivers (method is further called "simultaneous RTK", the common RTK method using one rover receiver is called "successive RTK"). It was tested because it is logically justifiable that even the RTK surveying have systematic errors the same or similar size in small areas, which will change over time. Its presence and size can then be suppressed by simultaneous measurement. There can be used of course and fast static method, but it requires post processing, the RTK can use a shorter observation time and work directly with the coordinates.

This article does not describe the principles of GNSS, which can be found in (Mervart, 1997) and in a simple way in (Láska et al, 2010).

\section{Implementation of a local survey network}

For testing purposes of individual GNSS methods has been built suitable surveying network with nearly ideal conditions for GNSS measurements and with mutual visibility for direct trigonometric measurements.

\subsection{Description of the network}

Surveying network was implemented by five points at a distance of $60 \mathrm{~m}-130 \mathrm{~m}$ apart village Mariánská (near town Jáchymov), on the crest of the hill Čimice (Fig. 1).
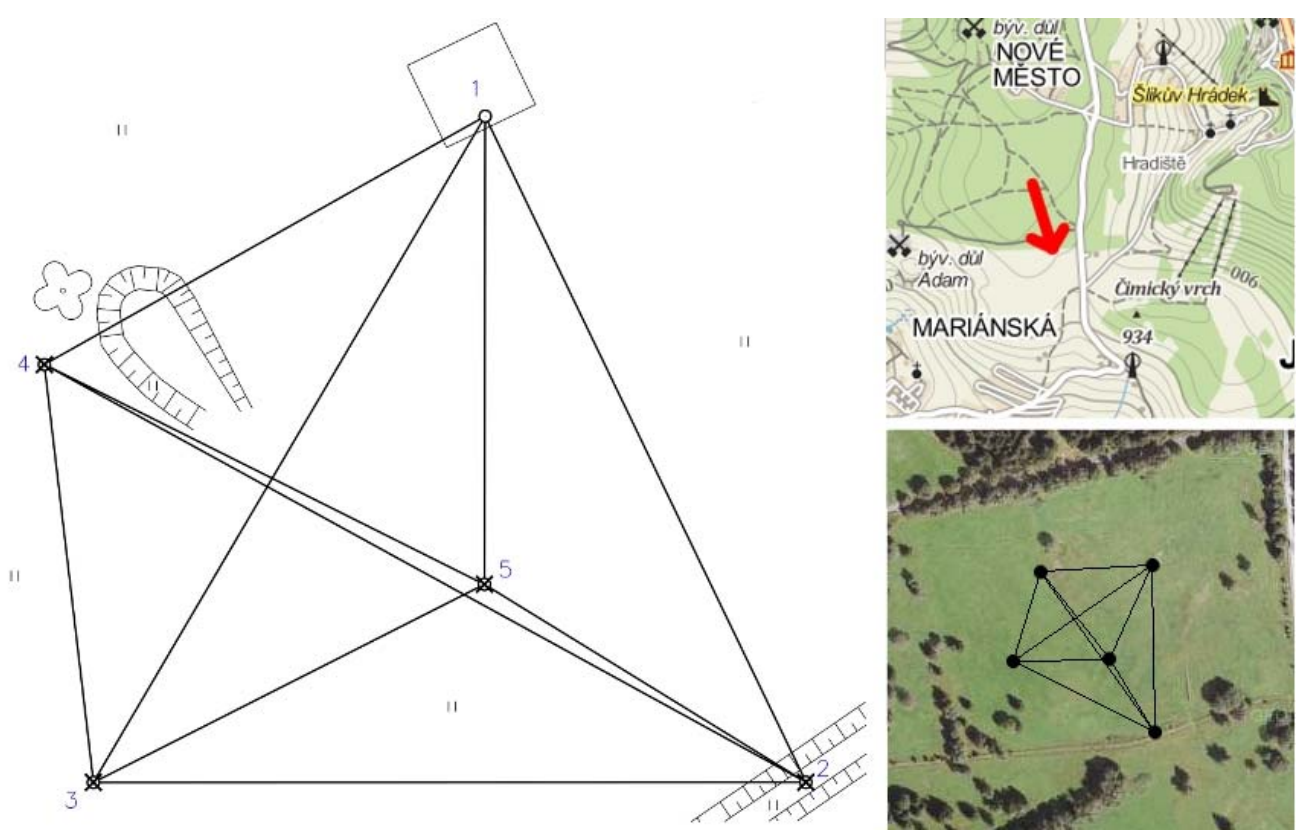

Fig. 1. Surveying network

Stabilization was carried out at the points 2 - 5 by long wooden pegs $(0.6 \mathrm{~m})$ with the nail in the head. Pegs were hammered into $0.45 \mathrm{~m}$ of compacted soil of the former mining area. Point 1 was stabilized by the nail in the concrete slab. 


\subsection{Trigonometric measurement of the survey network}

In order to determine the accuracy of GNSS measurement methods, it was necessary to determine very accurately size and shape of the entire surveying network. There was used a trigonometric method, measuring of the entire network was performed twice independently using Topcon GPT - 7501 instrument (standard deviation of the distance measurement to the prism is $2 \mathrm{~mm}+2 \mathrm{ppm}{ }^{*} \mathrm{D}$ and standard deviation of measured horizontal direction and zenith angle is 0.3 mgon) and a pair of prisms Leica GMP101 on centering bars with outriggers.

To determine the instrument height above the point a special tool was used, special instrument composed of precisely calibrated rod with a hollow, thin steel rod, washers into tripods and slide gauge. Both trigonometric measurements and subsequent experiments with GNSS receivers were realized in similar weather and temperature, namely the temperature was between $12^{\circ} \mathrm{C}-19^{\circ} \mathrm{C}$. Height of target marks on centering rods was determined experimentally before each measurement using invar leveling rods.

The actual trigonometric measurement was carried out in such a way that from every station were gradually measured four apex angles (always at the same time only two targets, because more of the target rods was not available), 4 oblique length and 4 zenith angles in two surveying groups. Number repeats was based on an analysis of accuracy before the measurement and it's modeling in the software PrecisPlanner (Štroner, 2010). Adjustment with the detection of outliers was done in Easynet software (Třasák, 2009). As a method of robust estimation to find the outlying measurements was used Huber's one and its application to geodetic measurements described in detail in (Třasák and Štroner, 2011) at a significance level $5 \%$. There was adjusted 528 observations totally and it was excluded 37 outlaying observations from the further least squares adjustment.

For further processing were adjusted coordinates of all five points transformed (only translation and rotation) into the coordinate system JTSK on average coordinate values determined by RTK measurement (described below). The resulting transformed coordinates and their standard deviations are shown in Tab. 1, where $s_{p}$ is standard deviation in position calculated by square root of the sum of the squares of standard deviations of $\mathrm{Y}, \mathrm{X}$ and $\mathrm{H}$.

Table 1. The resulting coordinates after the transformation (trigonometric measurement)

\begin{tabular}{|c|c|c|c||c|c|c|c|}
\hline $\begin{array}{c}\text { Point } \\
\text { No. }\end{array}$ & $\begin{array}{c}\mathrm{Y} \\
{[\mathrm{m}]}\end{array}$ & $\begin{array}{c}\mathrm{X} \\
{[\mathrm{m}]}\end{array}$ & $\begin{array}{c}\mathrm{H} \\
{[\mathrm{m}]}\end{array}$ & $\begin{array}{c}\mathrm{s}_{\mathrm{y}} \\
{[\mathrm{mm}]}\end{array}$ & $\begin{array}{c}\mathrm{s}_{\mathrm{x}} \\
{[\mathrm{mm}]}\end{array}$ & $\begin{array}{c}\mathrm{S}_{\mathrm{H}} \\
{[\mathrm{mm}]}\end{array}$ & $\begin{array}{c}\mathrm{s}_{\mathrm{p}} \\
{[\mathrm{mm}]}\end{array}$ \\
\hline 1 & 845859.3810 & 996781.1401 & 922.1346 & 0.16 & 0.16 & 0.11 & 0.25 \\
\hline 2 & 845878.2691 & 996892.7154 & 917.5222 & 0.17 & 0.13 & 0.12 & 0.25 \\
\hline 3 & 845967.3310 & 996829.5732 & 922.7111 & 0.14 & 0.15 & 0.10 & 0.23 \\
\hline 4 & 845936.4594 & 996773.0750 & 924.2940 & 0.15 & 0.14 & 0.10 & 0.23 \\
\hline 5 & 845900.9177 & 996839.5069 & 920.3862 & 0.15 & 0.13 & 0.08 & 0.21 \\
\hline
\end{tabular}

\section{GNSS measurements and processing}

Measurements were carried out in two days following after terrestrial network measurement. Tested methods of GNSS measurements were confined to the static method and fast RTK with simultaneous and successive measurement, all with different length of observations. 


\subsection{Equipment and instruments}

For the GNSS measurements were used five sets of apparatus Trimble Geo XR with Trimble Zephyr 2 antenna, which were mounted on a tripods and centered over the point by the optic plummet. The reciever is equipped by a 220-channel GNSS chip signal receiving systems GPS and GLONASS. More details can be found on the manufacturer's website (http://www.trimble.com/trimbleGeoXRgnss.shtml).

\subsection{GNSS static measurement procedure}

On each of the points of the network was placed one tripod with tribrach, carrier and the antenna, which was using an optical plummet centered over the point. The recording interval was set to 5 seconds (for a two-hour observation 15 seconds), elevation mask to $10^{\circ}$, PDOP mask to 6.0. Antenna height was entered directly into the controller and was determined using a standard tape measure (slope distance measurements automatically corrected in the device from the knowledge of the antenna dimensions). Received was both the GPS and GLONASS signals. Measurements were always carried out twice, in several observation lengths. The longest observation time was 2 hours. This one was followed by a shorter observations: 30,10 and 5 minutes.

\subsection{GNSS RTK measurement procedure}

Measurement was performed using the same equipment as in the case of the static method and also with centration precision control to avoid unwanted errors. Necessary corrections provided by networks of reference stations CZEPOS were downloaded from the internet via mobile phone to connect the controller with a SIM card. Observation periods were 5, 15, 30, 60 and 300 seconds. Measurement was carried out simultaneously (at the same time all 5 points) and also successively. Compliance of the time interval was assured by the signal given by assistant.

\subsection{Measurement processing}

Data obtained from static measurements were processed in the Trimble Business Center (TBC) version 2.81. Processing is carried out in two steps. It was first performed processing of repeated measurements of the same length using the broadcast observation ephemeris, and then using the precise ephemeris. After comparing the resulting coordinates, it was evident that the difference between the use of precise and broadcast ephemerides in tenths of millimeters and for further calculations were therefore used only broadcast ephemeris.

The result RTK measurements were directly coordinate system JTSK and no further processing was necessary.

\subsection{Determining the accuracy of the measurement results}

Measurement results - coordinates - were compared with the coordinates determined by the terrestrial geodetic measurements, which was due to its accuracy and the estimated accuracy GNSS measurement for the evaluation purposes considered to be flawless. The comparison was made for the $X$ and $Y$ coordinates by the congruent two-dimensional linear transformation, and separately for the height $\mathrm{H}$ 
(due to the assumption of lower accuracy) by the congruent one-dimensional transformation. Both types of the transformations were calculated with adjustment by the least squares method. After calculating of the each transformation key corrections were calculated, and then from it the individual sample standard deviations, which are listed below. Computational formula used to calculate standard deviation:

$$
s_{i}=\sqrt{\frac{\sum v_{i}^{2}}{n^{\prime}}}
$$

where $i$ represents each coordinate $(\mathrm{Y}, \mathrm{X}, \mathrm{H}), v$ residuals after transformation and $n$ ' is the number of redundant measurements (here number of transformed coordinates minus number of unknowns calculated in transformation key).

\section{Results}

In this section are given determined sample standard deviations describing the local coordinate precision of each tested method.

As a tested method was also utilized simultaneous RTK measurement, which can be regarded as unusual. To assess its possible significance testing was carried null hypothesis test of conformity standard deviations achieved by gradual and simultaneous RTK, there was used the one-tailed Fisher F-test at a significance level of $5 \%$. Furthermore, by the same test was verified provability of the different standard deviations obtained at differently long observations by one method also at a significance level of $5 \%$. Usage of the test is use of the test is described in detail in (Štroner and Hampacher, 2011).

\subsection{Static method}

The resulting standard deviations obtained by measuring of the static method were obtained by the processing of observations, measurement and determination of results as the quadratic average of two independent phases using broadcast ephemerides. Table 2 shows the period of observation and the corresponding standard deviations in each axis, as well as in the position. Standard deviations were obtained from the coordinate differences (residua) after the transformation to coordinates determined by the trigonometric method. The Table 3 contains the results for height showed in the same manner.

Table 2. The resulting standard deviations for $X, Y$ coordinates - static method

\begin{tabular}{|c|c|c|c|}
\hline $\begin{array}{c}\text { Length of } \\
\text { observation }\end{array}$ & $\begin{array}{c}\mathrm{s}_{\mathrm{y}} \\
{[\mathrm{mm}]}\end{array}$ & $\begin{array}{c}\mathrm{s}_{\mathrm{x}} \\
{[\mathrm{mm}]}\end{array}$ & $\begin{array}{c}\mathrm{s}_{\mathrm{p}} \\
{[\mathrm{mm}]}\end{array}$ \\
\hline 2 hours & 0.8 & 0.6 & 1.0 \\
\hline 30 minutes & 0.8 & 1.2 & 1.4 \\
\hline 10 minutes & 0.9 & 1.2 & 1.5 \\
\hline 5 minutes & 0.8 & 1.2 & 1.5 \\
\hline
\end{tabular}


Table 3. The resulting standard deviations for height coordinate - static method

\begin{tabular}{|c|c|}
\hline $\begin{array}{c}\text { Length of } \\
\text { observation }\end{array}$ & $\begin{array}{c}\mathrm{s}_{\mathrm{H}} \\
{[\mathrm{mm}]}\end{array}$ \\
\hline 2 hours & 1.8 \\
\hline 30 minutes & 2.3 \\
\hline 10 minutes & 2.3 \\
\hline 5 minutes & 2.5 \\
\hline
\end{tabular}

From both tables it is clear that the accuracy of measurement increases as expected with the observation time. Due to the low number of redundant measurements the conclusion is not statistically provable. When comparing the obtained standard deviation for the two-hour and five-minute observation, the ratio of squared standard deviations had to be for positional deviation at least 2.98 (14 redundant variables in the two standard deviations at a significance level of $5 \%$ ), there is only 2.25 , for standard deviation in height is a test criterion 1.9 and critical value 4.4 (only 8 of redundant measurements).

\subsection{Simultaneous measurement of RTK}

Standard deviations simultaneous RTK measurements are calculated as the quadratic mean of six independent stages. The resulting table (Table 4 and Table 5) are similar to the static method.

Table 4. The resulting standard deviations for $X, Y$ coordinates - simultaneous RTK

\begin{tabular}{|c|c|c|c|}
\hline $\begin{array}{c}\text { Length of } \\
\text { observation }\end{array}$ & $\begin{array}{c}\mathrm{S}_{\mathrm{y}} \\
{[\mathrm{mm}]}\end{array}$ & $\begin{array}{c}\mathrm{S}_{\mathrm{x}} \\
{[\mathrm{mm}]}\end{array}$ & $\begin{array}{c}\mathrm{s}_{\mathrm{p}} \\
{[\mathrm{mm}]}\end{array}$ \\
\hline 5 minutes & 2.7 & 1.9 & 3.3 \\
\hline 1 minute & 2.5 & 1.9 & 3.2 \\
\hline 30 seconds & 2.9 & 2.0 & 3.6 \\
\hline 15 seconds & 2.7 & 1.7 & 3.2 \\
\hline 5 seconds & 3.2 & 2.3 & 3.9 \\
\hline
\end{tabular}

Table 5. The resulting standard deviations for height coordinate - simultaneous RTK

\begin{tabular}{|c|c|}
\hline $\begin{array}{c}\text { Length of } \\
\text { observation }\end{array}$ & $\begin{array}{c}\mathrm{S}_{\mathrm{H}} \\
{[\mathrm{mm}]}\end{array}$ \\
\hline 5 minutes & 6.2 \\
\hline 1 minute & 5.3 \\
\hline 30 seconds & 6.2 \\
\hline 15 seconds & 5.9 \\
\hline 5 seconds & 4.2 \\
\hline
\end{tabular}

According to the resulting standard deviations describing the accuracy of the results simultaneous RTK methods suggest that accuracy is visually different, however dispersion of results indicate that the differences are not great and in terms of real achievable accuracy practically negligible, as confirmed by a statistical test. It was measured in six stages, the number of redundant measurements is for position 
$42, \mathrm{~F}_{\text {krit }}(\alpha / 2,42,42)=1,85$; squared ratio of the maximum and minimum standard deviation does not exceed this critical value, is only 1.49 .

For height, the number of redundant measurements is $24, F_{\text {krit }}(\alpha / 2,24,24)=2.27$, and the maximum test criterion when comparing five-second and five-minute observation $F=2.18$ does not exceed the critical value. Standard deviation at fivesecond observation deviates significantly from the trend of others, using another smallest - the one-minute observation standard deviation, the test criterion is only $\mathrm{F}=$ 1.37 and again does not exceed a critical value.

Overall, the results of this method also show that longer measurement time does not bring the expected increase in accuracy.

\subsection{Successive measurement of RTK}

Standard deviations simultaneous RTK measurements are calculated as the quadratic mean of five independent stages. The resulting table (Table 6 and Table 7) are similar to the static method.

Accuracy of position determination due to expectation optically grows with period of observation, for statistical evaluation is the maximum value of the test criterion $\mathrm{F}=$ 1.48, when compared fifteen seconds and five-minute observation, the critical value is $F_{\text {krit }}(\alpha / 2,35,35)=1.96$, and the achieved difference in accuracy is again inconclusive. For height coordinate is the maximum value of the test criterion $F=$ 1.43 , when comparing thirty seconds and five-minute observation, and it implies, that according to critical value $\mathrm{F}_{\text {krit }}(\alpha / 2,20,20)=2.47$ the difference in achieved precision also unprovable.

Table 6. The resulting standard deviations for $X, Y$ coordinates - successive RTK

\begin{tabular}{|c|c|c|c|}
\hline $\begin{array}{c}\text { Length of } \\
\text { observation }\end{array}$ & $\begin{array}{c}\mathrm{s}_{\mathrm{y}} \\
{[\mathrm{mm}]}\end{array}$ & $\begin{array}{c}\mathrm{s}_{\mathrm{x}} \\
{[\mathrm{mm}]}\end{array}$ & $\begin{array}{c}\mathrm{s}_{\mathrm{p}} \\
{[\mathrm{mm}]}\end{array}$ \\
\hline 5 minutes & 2.2 & 4.1 & 4.6 \\
\hline 1 minute & 3.3 & 4.3 & 5.4 \\
\hline 30 seconds & 3.5 & 3.6 & 5.0 \\
\hline 15 seconds & 3.9 & 4.0 & 5.6 \\
\hline 5 seconds & 4.1 & 3.1 & 5.2 \\
\hline
\end{tabular}

Table 7. The resulting standard deviations for height coordinate - successive RTK

\begin{tabular}{|c|c|}
\hline $\begin{array}{c}\text { Length of } \\
\text { observation }\end{array}$ & $\begin{array}{c}\mathrm{S}_{\mathrm{H}} \\
{[\mathrm{mm}]}\end{array}$ \\
\hline 5 minutes & 9.6 \\
\hline 1 minute & 9.6 \\
\hline 30 seconds & 9.7 \\
\hline 15 seconds & 8.1 \\
\hline 5 seconds & 9.1 \\
\hline
\end{tabular}

\subsection{Comparison of the tested methods}

In addition to assessing the individual methods there can be tested further reciprocal comparison of the two RTK methods and static method. In terms of statistical comparison is a static method both in position and at a height of more 
accurate, which can be documented by comparing the results achieved in the shortest observation 5 minutes $\left(\mathrm{s}_{\mathrm{p}}=1.5 \mathrm{~mm} ; \mathrm{s}_{\mathrm{H}}=2.5 \mathrm{~mm}\right)$ and the best result achieved by the simultaneous RTK method $\left(\mathrm{s}_{\mathrm{p}}=3.3 \mathrm{~mm} ; \mathrm{s}_{\mathrm{H}}=4.2 \mathrm{~mm}\right)$. Test criteria have then the value $F_{p}=2.77$ and $F_{H}=1.62$, critical values are $F_{\text {krit_p }}(\alpha / 2,42,14)=$ 2.67 and $F_{\text {krit_H}}(\alpha / 2,24,8)=3.95$.

Statistically is therefore determination of the position more precise, for the determination of the height finding cannot be proved due to the small number of redundant measurements.

There can be also compared the results obtained by simultaneous and successive RTK method, the results are shown in Tab. 8 and Tab. 9th

Table 8. The comparison of the precision reached by successive and simultaneous RTK method - position

\begin{tabular}{|c|c|c|c|}
\hline $\begin{array}{c}\text { Length of } \\
\text { observation }\end{array}$ & $\begin{array}{c}\text { Simultaneous } \\
\mathrm{s}_{\mathrm{p}} \\
{[\mathrm{mm}]}\end{array}$ & $\begin{array}{c}\text { Successive } \\
\mathrm{s}_{\mathrm{p}} \\
{[\mathrm{mm}]}\end{array}$ & $\begin{array}{c}\text { Testing } \\
\text { criterion } \\
\mathrm{F}\end{array}$ \\
\hline 5 minutes & 3.3 & 4.6 & 1.94 \\
\hline 1 minute & 3.2 & 5.4 & 2.85 \\
\hline 30 seconds & 3.6 & 5.0 & 1.93 \\
\hline 15 seconds & 3.2 & 5.6 & 3.06 \\
\hline 5 seconds & 3.9 & 5.2 & 1.78 \\
\hline
\end{tabular}

The critical value of the test criteria is for position $F_{\text {krit_p}}(\alpha / 2,42,35)=1.92$. This value is exceeded by all testing criteria except the one the for five-second observation.

Table 9. The comparison of the precision reached by successive and simultaneous RTK method - height

\begin{tabular}{|c|c|c|c|}
\hline $\begin{array}{c}\text { Length of } \\
\text { observation }\end{array}$ & $\begin{array}{c}\text { Simultaneous } \\
\mathrm{S}_{\mathrm{H}} \\
{[\mathrm{mm}]}\end{array}$ & $\begin{array}{c}\text { successive } \\
\mathrm{S}_{\mathrm{H}} \\
{[\mathrm{mm}]}\end{array}$ & $\begin{array}{c}\text { Testing } \\
\text { criterion } \\
\mathrm{F}\end{array}$ \\
\hline 5 minutes & 6.2 & 9.6 & 2.40 \\
\hline 1 minute & 5.3 & 9.6 & 3.28 \\
\hline 30 seconds & 6.2 & 9.7 & 2.45 \\
\hline 15 seconds & 5.9 & 8.1 & 1.88 \\
\hline 5 seconds & 4.2 & 9.1 & 4.69 \\
\hline
\end{tabular}

The critical value of the test criteria is for height $F_{\text {krit_p }}(\alpha / 2,24,20)=2.41$. This value is practically exceeded by all testing criteria except the one for fifteen-second observation.

On the basis of the performed testing there can be adopted result, that simultaneous RTK method provides some increased accuracy, but the possibility of the practical use of this method is limited by the necessity of use of at last two GNSS receivers simultaneously. 


\section{Conclusions}

The article presents the results of a simple experiment realized to determine the local relative precision of GNSS measurements by different methods, namely rapid static and RTK method (in two variations), each with different lengths of observation. Looking in tables with results it is clear, that static method is undoubtedly the most accurate one from tested methods, followed by the simultaneous RTK method, which is more accurate than successive RTK method.

Qualitative difference between simultaneous and successive RTK measurements can easily be justified logically, measurements taken simultaneously collects data from the same satellites at the same layout on the horizon and in acting (almost) the same atmospheric influences. Precision of the measurements at each point is loaded by the similar errors that occur during joint processing to all points in the same way and disrupt the relative relationship between the points only minimally.

The tested methods are on the basis of conducted simple test suitable also for use in case of requirement of higher than sub centimeter precision. This can be achieved in the case of short distances among measured points. Surprisingly high relative accuracy can be achieved using RTK even when using very short observables and the achievable accuracy may be still further increased by using simultaneous RTK method

\section{Acknowledgement}

This research was supported by internal grant of CTU in Prague SGS13/059/OHK1/1T/11 "Optimization of 3D data acquisition and processing for the needs of engineering geodesy".

\section{References}

Královič, J. (2013). Testing of local precision of GNSS receivers Trimble GeoXR. CTU in Prague. [Diploma thesis]. (in Czech).

Láska, Z., Tešnar, M., Slabý, J. and Sukup, J. (2010). Global navigation satellite systems and their use in practice. Center for the development of research of advanced control and sensor technologies, Institute of Automation and measurement technology, Brno University of Technology, 2010.

http://www.crr.vutbr.cz/kurzy-seminare/merici-systemy/seminar-globalni-navigacnisatelitni-systemy-jejich-vyuziti-v-praxi. (in Czech).

Mervart, L. (1997). Basics of GPS. CTU in Prague. (in Czech).

Vilímková, M. (2007). Accuracy Tests of the CZEPOS. Geodetický a kartografický obzor. 2007, 53, No. 4. ISSN 0016-7096. (in Czech).

Štroner, M. (2010). Development of software for planning of the precision of geodetic measurements PrecisPlanner 3D. Stavebni obzor, 2010, 19, No. 3, pp. 92-95. ISSN 1210-4027. (in Czech).

Štroner, M. and Hampacher, M. (2011). Processing and analysis of measurements in engineering surveying. 1. ed. Prague: CTU Publishing House, 2011. 313 p. ISBN 978-80-01-04900-6. (in Czech). 
Třasák, P. (2009) Software EasyNet 2.2. Ing. Pavel Třasák [online]. 2009, 06.11.2012 [cit. 2012-11-22].

http://k154.fsv.cvut.cz/ trasak/handmade/easynet.html.

Třasák, P. and Štroner, M. (2011). Robust Adjustment Methods. Geodetický a kartografický obzor. 2011, 57, No. 7. ISSN 0016-7096. (in Czech).

Urban, R., Štroner, M., and Kovařík, K. (2013). Comparison of GNSS Measurement Accuracy in the Reference Stations Network in the Territory of Prague. Geodetický a kartografický obzor. 2013, 59, No. 3. ISSN 0016-7096. (in Czech).

\section{Authors:}

doc. Ing. Martin Štroner ${ }^{1)}$, Ph.D., martin.stroner@fsv.cvut.cz

Ing. Rudolf Urban ${ }^{1)}$, Ph.D., rudolf.urban@fsv.cvut.cz

Ing. Jakub Královič ${ }^{1)}$, jakubkralovic@seznam.cz

1) CTU in Prague, Faculty of Civil Engineering, Department of Special Geodesy,

Czech Republic 